Article

\title{
An Empirical Study on Sustainable Agriculture Land Use Right Transfer in the Heihe River Basin
}

\author{
Ye Sun ${ }^{1(1)}$ and Tomohiro Akiyama ${ }^{2, *}$ (1) \\ 1 Graduate Program in Sustainability Science-Global Leadership Initiative, Graduate School of Frontier Sciences, \\ The University of Tokyo, Kashiwa City 277-8563, Japan; yesun@s.k.u-tokyo.ac.jp \\ 2 Department of Socio-Cultural Environmental Studies, Graduate School of Frontier Sciences, \\ The University of Tokyo, Kashiwa City 277-8563, Japan \\ * Correspondence: akiyama@k.u-tokyo.ac.jp; Tel.: +81-04-7136-4889
}

Received: 14 December 2017; Accepted: 5 February 2018; Published: 9 February 2018

\begin{abstract}
Agriculture land use right transfer (ALURT) is a new policy designed to meet the demand of the sustainable development of agriculture in China. In the Heihe river basin (HRB), ALURT has also recently been introduced to cope with the emerging challenges in agriculture. In this paper, we empirically study the long-term viability of this new policy in HRB using a sustainability assessment. We collect the documents of ALURT contracts, statistical data of ALURT performance, and conduct interviews with its users. The main finding is that the centralized institutional structure of ALURT in HRB compromises its long-term viability. In particular, the power imbalance under the regulation of the intermediate agency, which causes the dissatisfaction of the participants, is threatening the application of the ALURT policy in the long run. Therefore, we suggest that the role of the intermediate agency in ALURT needs to be redefined, to better serve the sustainable development of agriculture in HRB.
\end{abstract}

Keywords: land use right transfer; Heihe river basin; agriculture; policy; sustainability

\section{Introduction}

Agriculture land reform in China has been intensively started to challenge social, economic, and environmental problems [1]. Recently, due to economic development and urbanization, the labor force of agriculture has been decreasing. Especially, the youths in the rural area are draining away from the agriculture sector to the urban job market, forming a hollowing rural community with left-behind elders and children [2-5]. To sustain the huge population of China, the challenge of sufficient agricultural production by a smaller labor force has been imposed. Moreover, other conditions, such as income growth, intensive technology management, and natural environment preservation, are also important to the sustainability of an agriculture area. All these changes have already exerted great pressure on the traditional labor-intensive household responsibility system [1]. As a response, agriculture land use right transfer (ALURT) has been initiated to promote the agricultural modernization required to face these challenges. Though farmland transfer was previously prohibited, the new ALURT policy allows the farmers to transfer their use rights of the farmland to others. The ALURT system was firstly set up in 2003 [6], and has been promoted intensively all over the country since 2008 [7]. From the viewpoints of three pillars in sustainability science [8], the ALURT policy was adopted because of several potential benefits including: (i) Economic benefits: by transferring the land use right, large-scale production can be carried out, and the technology investment becomes more profitable due to economies of scale. As a result, ALURT is promising in terms of income growth for both sides of its users; (ii) Social benefits: ALURT requires less labor in farmland, which can cope with the agricultural labor shortage due to urbanization and labor migration; (iii) Environmental benefits: ALURT with 
efficient irrigation technology has the potential to save water. In addition, some cross-benefits can be: (i) Socioeconomic benefits: off-farm employment has been positively correlated with a higher income in previous empirical studies [9-11]. However, the income inequity between off-farm and on-farm work is not good in terms of poverty alleviation or sustainable agriculture development [12]. ALURT encourages off-farm employment and increases on-farm income. As a result, the income of households can be increased from both off-farm and on-farm work, without exacerbating the inequity between them; (ii) Social-environmental benefits: based on [13,14], off-farm employment is correlated with less water usage in agriculture, which is an incentive when applying ALURT to a water scarce area; (iii) Ecological-economic benefits: with a shift from labor-intensive to technology-intensive agriculture, the investment in water-saving technology becomes more practical in terms of capital returns. On the other hand, due to the labor shortage in a household, some agricultural land is no longer cultivated by its owners. The condition of the abandoned farmland usually deteriorates and environmental problems occur. In ALURT, the abandoned land can be reclaimed to produce economic value, while the land condition is preserved at the same time. Hence, potential environmental deterioration can be prevented. To summarize, ALURT has the potential to be a promising policy in promoting the sustainable development of agriculture in China.

The primary objective of this study is to understand the long-term viability of ALURT in the Heihe river basin in China with a sustainability assessment. In fact, many sustainability assessment frameworks have been proposed in recent decades (see examples in [15-19]). However, no single sustainability assessment on ALURT in China has been systematically conducted. This research gap is due to the fact that both sustainability assessments and ALURT are relatively new emerging topics. Accordingly, the combination of the two can possibly generate rich interactions and insights. The secondary objective is to contribute to the empirical literature on problems of ALURT with the firsthand data. A previous study has already pointed out the potential problems in a conceptual way, such as the regulation of contracts and the supervision procedure [7]. Some other research has examined the relationships between various factors and the willingness of land transfer based on the secondary nation-wide data [20]. However, few empirical studies with firsthand data have been conducted to closely examine the current performance of ALURT. In addition, studies on ALURT policy in the Heihe river basin have not yet been conducted because ALURT has only recently been developed in this area, emerging in 2009.

The main finding of this research is that ALURT is currently under a centralized control, and the land use right transfer can only be conducted through a third party (usually the village collective). This is partly because a sound land trade market has not yet emerged in China [1,6,7]. Although ALURT is initialized to benefit both the farmers and the collectors, the centralized mode does not allow direct trading between farmers and collectors. This further leads to the problem of an imbalanced power in the management of ALURT by a third party. In particular, the third party has the power to draft contracts so that it exempts itself from any essential responsibility. Accordingly, it has no incentives to monitor or facilitate the performance of ALURT due to being free of duty. The consequence is the slowdown of progress in ALURT within five years after its initialization. Results from both statistical data and interviews confirmed the difficulties in carrying out ALURT in the future.

This paper is organized as follows: In Section 2, the research area, the Heihe river basin, will be introduced, as well as the methods. In particular, we follow a sustainable development framework with data collected from the contracts, statistics, and interviews. In Section 3, the results derived from the content of contracts, the statistics of performance, and the interviews of users will be presented respectively. In Section 4, the long-term viability of ALURT will be discussed under general concepts of sustainability to help interpret the results. The improvement of the institutional structure of ALURT will also be proposed to make it a better instrument for the sustainable development of agriculture in the Heihe river basin. In Section 5, the key conclusions are summarized. 


\section{Materials and Methods}

\subsection{Research Area}

The Heihe river basin (HRB) in the northwest of China, is an oasis inside an arid area located on the ancient Silk Road (see Figure 1a). Historically, it has been an agricultural area with many irrigation canals that have been built to maintain the livelihoods with limited water resources [21]. According to [22,23], the agricultural land in HRB has an annual expansion rate larger than $1 \%$, lasting for more than 25 years from 1986 to 2011, because of the local economic development. In HRB, the Zhangye district, located in the middle reach of the Heihe river (See Figure 1b), is one of the places that has seen the largest agriculture land expansion since 1986 [22]. Moreover, the Zhangye district accounts for about $93 \%$ of all the water consumption from the river, within which $94 \%$ of the water is for agricultural use [24]. On the other hand, the Ministry of Water Resources designated Zhangye district as a pilot area for a water saving society after several attempts of the water use right system [25] and Green for Grain Project [26]. All these efforts are aimed at realizing the sustainability of HRB, which refers to sufficient agricultural production and income growth under the conditions of less labor, more technology intensive management, and no environmental deterioration.

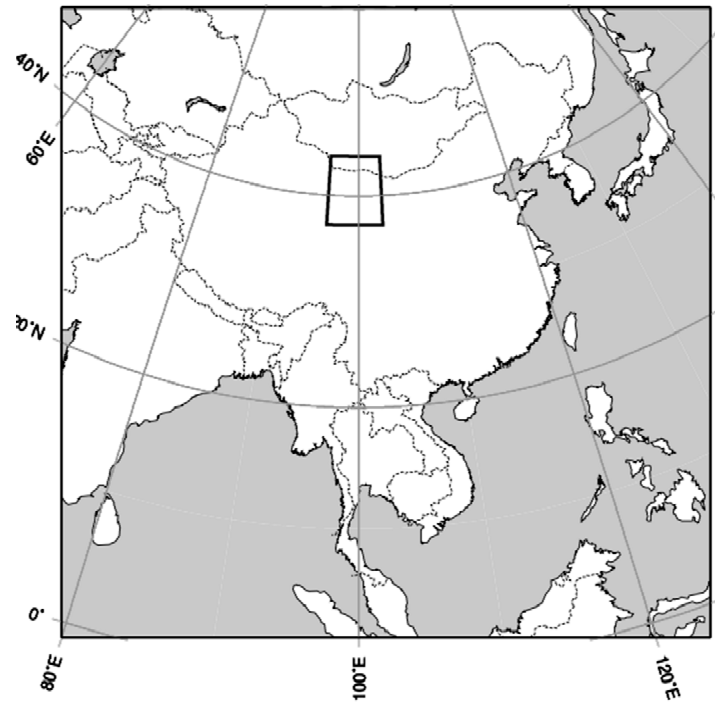

(a)

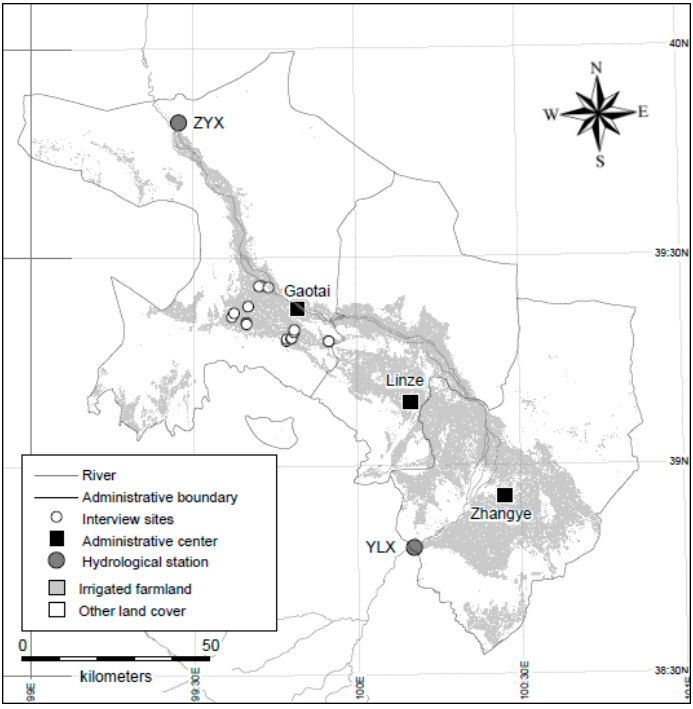

(b)

Figure 1. (a) The location of HRB in China; (b) The map of Zhangye district. The Gaotai County is shown in the map. The white circles denote the data collection sites.

Although this area has been rapidly developed, the large expansion of agricultural land in Zhangye district has already suppressed the current oasis ecosystem and groundwater, which potentially threatens the sustainable development of HRB [23,27-29]. Nonetheless, Zhangye district is still planned to be the second largest agricultural exploitation area with a new high technological industry throughout the country [30]. Consequently, the agricultural production capability of Zhangye district will not be decreased in the long run [26]. On the other hand, some efforts to cope with the water efficiency issue, such as the tradable water right systems, are not well enforced [31], and water market transactions are virtually absent [32] due to a low participation rate [33]. For the sustainability of HRB, alternatives have been considered. For example, there are political instruments to help farmers switch from water-intensive crops [25,34], or to encourage farmers to enlarge the land area under their management [25,30]. Accordingly, the ALURT policy also becomes a candidate to assist the sustainable development in HRB. 
We select the Gaotai County located in Zhangye City as our study area because the ALURT policy has been initiated intensively and promptly in this county. In Gaotai County, we mainly focus on two towns, Nanhua and Luotuocheng (NH, LTC), in which we have collected substantial data from each village for an analysis (see the data collection spots in Figure 1b). We also include Xuanhua (XH) town with interview data because it started ALURT in 2009, which is the earliest implementation among all towns in Gaotai County. Because both NH and LTC started ALURT after 2010 and this field survey was done in 2014, we examine 2011 to 2014 as our main time span for the assessment.

\subsection{Research Framework}

As modernized agriculture in Zhangye district and an active role of the state could possibly achieve sustainability in HRB [35], we use the SURF framework for the assessment of the long-term viability of the ALURT policy for a green economy based on [36]. The SURF framework treats the three pillars of sustainability (environmental, economic, social considerations) as the background, where it focuses on the "gears" driving the sustainable development from four elements: supply chain, users, relations, and future (SURF). We selected this framework for ALURT because our objective is to evaluate the long-term viability of the policy based on the current institutional structure, users, and their relations. This framework provides us with the elements, concepts, and tools to focus on our main objective. Our assumption is: if the "gears" are driven properly, then the output of sustainable development by this policy can be promising in the long run. In other words, if the policy could not be continued due to some critical problems, no matter how many benefits it could possibly generate, it still would not lead us to the sustainable development we are looking for. Therefore, we will closely examine the supply chain in the land transfer activity, the users' satisfaction, the institutional relations, and the future trend of this policy under this framework.

\subsection{Methods}

According to the four elements defined in the SURF framework, we deploy a three-fold method to fulfill the investigations of each.

First of all, an analysis is conducted for the supply chain indicated in the contents of ALURT contracts. Specifically, the institutional structure, roles of farmers, contractors, and other users in the supply chain are identified. Second, a quantitative analysis based on the statistical data of ALURT performance is conducted. Some aspects of the current status and trend of ALURT are obtained, such as the land area, crop type, and land rent. Third, the interviews of the users' satisfaction level in ALURT, and the willingness to continue ALURT in future are conducted. The users' satisfaction is crucial to the future of the ALURT policy because it affects the participation rate in the long run. Some similar projects, for example, the water trade market, though good in its intention, eventually turned out to have little impact due to a low participation rate [33]. With the three methods mentioned above, the SURF framework is engaged to identify the problems related to the long-term viability of this policy.

Data were collected in our fieldwork between 3 August and 15 August 2014. Three towns (LTC, $\mathrm{NH}, \mathrm{XH}$ ) in Gaotai County were visited. The data types and sizes are shown in Table 1.

Table 1. The data collected in three towns of Gaotai County, Zhangye.

\begin{tabular}{cccc}
\hline Town & Contract Data & Statistical Data $^{\mathbf{1}}$ & Interview Data \\
\hline LTC & 82 & 10 & $18^{2}$ \\
NH & N/A & 13 & $11^{3}$ \\
XH & N/A & N/A & $9^{4}$ \\
\hline
\end{tabular}

\footnotetext{
1 Statistical data sets are village based: 10 villages in LTC, 13 villages in $\mathrm{NH} .{ }^{2}$ Composition of interviewees: 1 government, 2 big collectors, 15 farmers. ${ }^{3}$ Composition of interviewees: 1 government, 1 big collector, 9 farmers.

4 Composition of interviewees: 1 government, 8 farmers.
} 


\section{Results}

\subsection{Results from the Structure of ALURT Contract}

Figure 2 indicates the institutional structure of the supply-chain in ALURT. All the farmers have to sign contracts with an intermediate agency in order to participate in ALURT. The intermediate agency is different from village to village. For example, in the village QJ in LTC town, the intermediate agency is an organization of corn cultivation cooperatives, whereas in a village called XF in NH town, the intermediate agency is the village committee. The intermediate agency negotiates conditions and drafts the contracts with the farmers and collectors, respectively. As the procedure in ALURT, only the intermediate agency has access to the collectors and can negotiate with collectors. Consequently, only the intermediate agency has the right to choose one collector over another. The farmers are not able to negotiate with collectors and choose different collectors themselves.

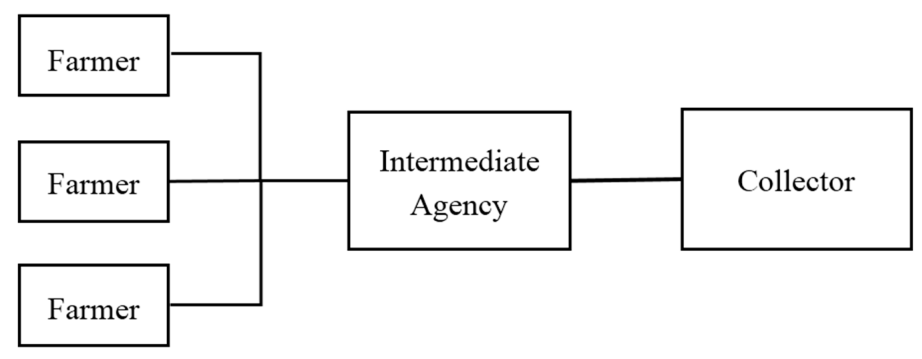

Figure 2. The illustration of the supply-chain and relationship of the users in ALURT through the contract content analysis in Gaotai County, Zhangye.

The analysis of the contracts shows that there exists a significant difference between the contracts for farmers and those for collectors. The important points are: first, the contract periods are different. The intermediate agency drafted the contracts with farmers for five years, whereas the contracts with collectors for only three years. Second, the rents and payment methods are different. For example, the intermediate agency signed the contracts with farmers at a fixed rate of $15,000 \mathrm{RMB} / \mathrm{ha}$. However, the contracts between the intermediate agency and the collectors are at a floating rate according to the market price, starting from 15,000 RMB/ha. In terms of the payment methods, the payment made from collectors cannot go directly to the accounts of farmers. In fact, the intermediate agency collected all the money in its account first and the payment to farmers was made one month later. Third, the conditions of renewing contracts are different. In the case of the contracts with farmers, the intermediate agency has the power to decide whether the contracts are renewed. It is written in the contracts, that the privilege is on the intermediate agency side. Even if the farmers are willing to continue with the same collector, they cannot do so if the intermediate agency prefers another collector for the new period. In the case of the contracts with collectors, no terms regarding renewal are specified, which indicates that the intermediate agency can switch to any collector flexibly.

Nonetheless, when ALURT has the responsibilities of land management, the intermediate agency is free of responsibility. For example, in the contracts with farmers, though the intermediate agency seems to have the duty to restore the land to its initial condition before the contract is terminated, the agency drafts its contracts with collectors in a way requiring the collectors to fulfill the responsibility. Similarly, in the contracts with collectors, the intermediate agency seems to have the duty to pay the expense for well digging and maintenance fee for electrical equipment, but it actually requires the farmers to cover it as one term in the contracts with farmers. In fact, because only the intermediate agency is able to make contracts with farmers and collectors, respectively, it becomes convenient to reassign the duty of land maintenance to the collectors, and in the same way, the duty of equipment maintenance and well digging to the farmers. This issue in the contracts was confirmed in the interviews with farmers, who were responsible for the well digging, as well as in the interviews with 
collectors, who were required to restore the land condition. As a result, the intermediate agency becomes a role in the supply chain with the most power in terms of the regulation and is free of duty in ALURT management.

\subsection{Results from Statistical Data of Performance of ALURT}

In this section, the statistical data are analyzed from social, economic, and environment aspects of sustainability. The social aspect is the urbanization and off-farm population growth indicated in the trend of land transfer activity. The economic aspect is income growth for farmers indicated in the trend of the land rent. The environmental aspect is the crop variability cultivated in the transferred land.

- Social aspect: Land transfer activity

Zhangye district has a total farmland area of 239 thousand hectares, including six counties [37]. Figure 3a shows the transferred land area in total and in each village in LTC town in 2013 and 2014, and Figure 3b shows the data for NH town from 2011 to 2013, respectively. In both towns, decreasing trends in transferred land area can be observed. In LTC town, the newly transferred land decreases from around 900 ha in 2013 down to less than 600 ha in 2014, with a more than 33\% decrease rate. A similar trend in NH town shows a slight decrease from around 500 ha in 2011 to roughly 400 ha in 2012, followed by a sharp 75\% decrease down to only 100 ha in 2013.

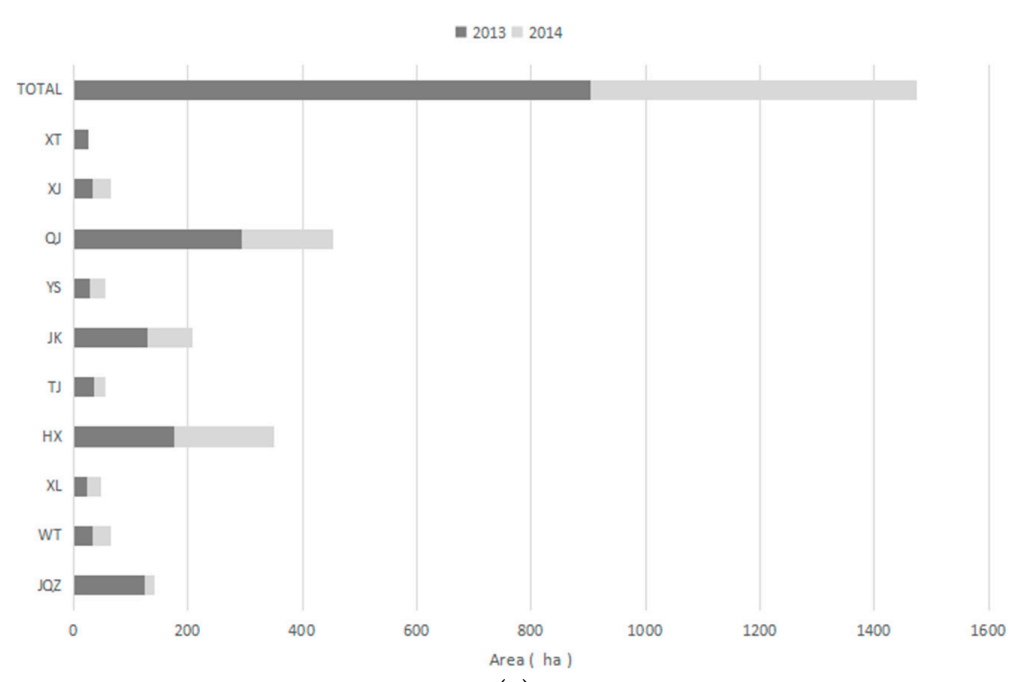

(a)

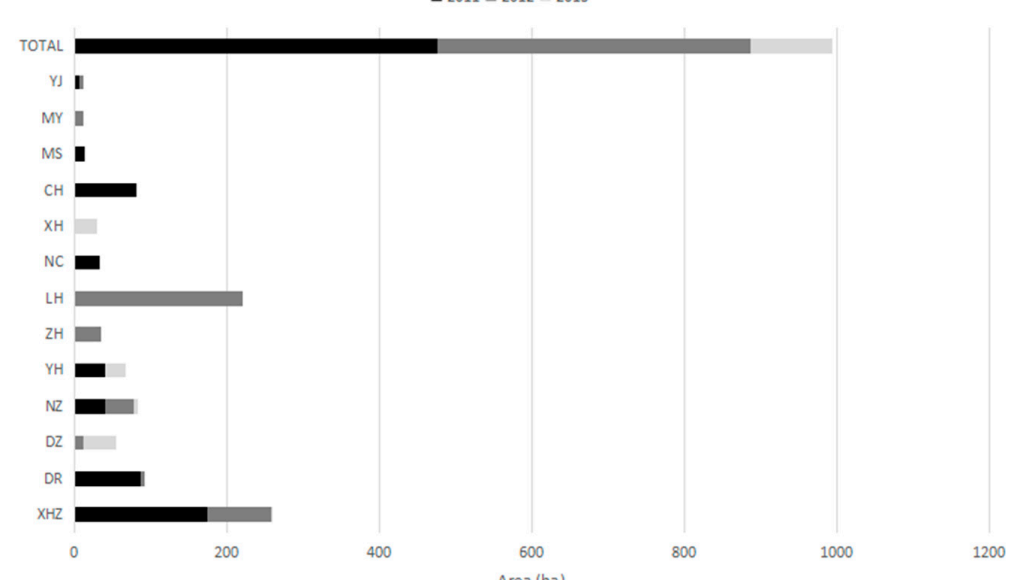

(b)

Figure 3. Land area transferred in a town as total and in different villages of the town; (a) LTC town in 2013 and 2014; (b) NH town from 2011 to 2013. 
In each town, the newly transferred land was only from a small number of villages. For example, only two villages in LTC town, namely QJ and HX, increased their newly transferred land area significantly, out of the total 10 villages in 2014. All other villages only contributed a small fraction to the growth of transferred land. As in NH town, a similar pattern can be observed in 2012, with most newly transferred land coming from two villages, namely LH and XHZ, out of the total 13 villages. The XHZ extended ALURT significantly in 2012, while the LH only started ALURT in 2012. Moreover, most of the villages stopped transferring their farmland in 2013, with the exception of three (DZ, YH, $\mathrm{XH}$ ) who extended a small fraction in 2013. As a reference, by the end of 2014, the total area of the transferred farmland in Gaotai County had reached more than 10,000 ha, occupying $11.2 \%$ of total farmland area [38]. However, from the trend of ALURT in our data, the growth has already slowed down significantly.

- Economic aspect: Rent as incomes for the farmers

Figure 4a shows the rent by villages in LTC town in 2014. The range of rent is from $9750 \mathrm{RMB} / \mathrm{ha}$ in $\mathrm{XJ}$ to $16,500 \mathrm{RMB} /$ ha in $\mathrm{XT}$, with an almost 1.7 times difference. Four out of the ten villages had reached a rent rate over $15,000 \mathrm{RMB} /$ ha by 2014 . On the other hand, Figure $4 \mathrm{~b}$ shows the land rent by villages in NH town from 2011 to 2013. Several important facts can be observed in the rent distribution and trend. First, in the early year of 2011, the rent was much lower, ranging from $7500 \mathrm{RMB} / \mathrm{ha}$ to $10,500 \mathrm{RMB} / \mathrm{ha}$. Second, the rent has been increased year by year as a general trend. The only exception is the village DR, who decreased its rent by $1500 \mathrm{RMB} /$ ha/year. Third, a high rent rate has been achieved, as $54 \%$ (seven out 13 villages) had passed over a rate of 12,000 RMB/ha during the study period. Overall, the land rent indicates an income growth of farmers in general. However, differences among villages did exist.

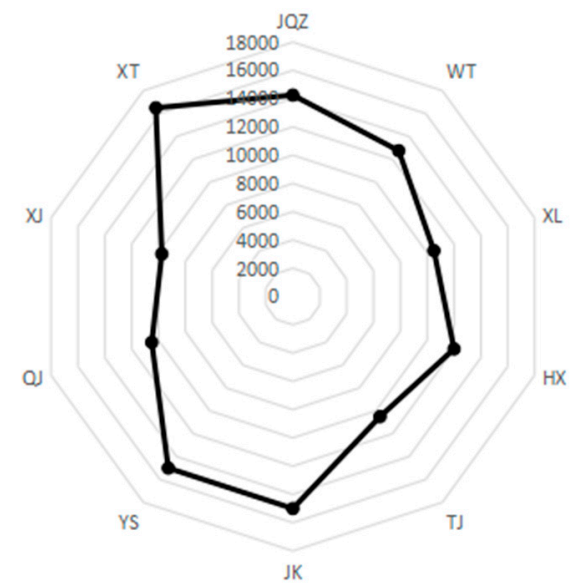

(a)

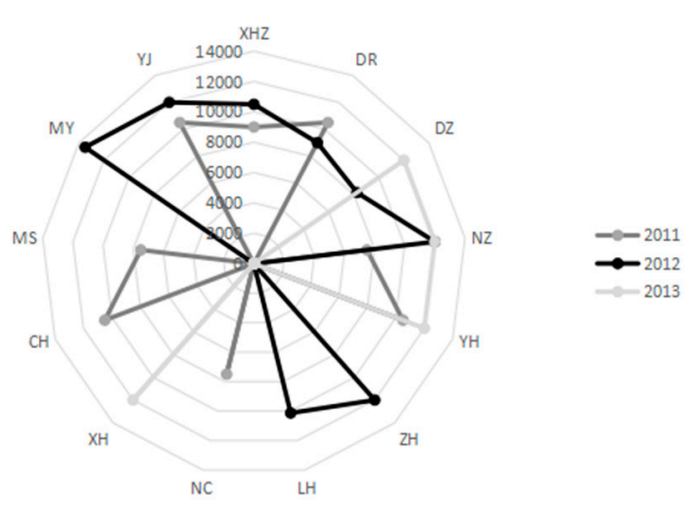

(b)

Figure 4. The rent of transferred agricultural land (RMB/ha) (a) in LTC town by villages in 2014; (b) in NH town by villages from 2011 to 2013.

\section{- Environmental aspect: crop variety in the transferred land}

Figure 5 shows the crop types cultivated by the collectors in the transferred land in LTC town in 2014. The ratio indicates that one cash crop dominates others in the land area, as the corn took up almost half of the transferred farmland for its cultivation (followed by onion in $28 \%$, seed corn in $19 \%$, and seed sun flower in only $4 \%$ of the farmland). According to the detailed data of the transferred farmland area by villages, the corn occupied around 430 ha from five out of 10 villages. The onion occupied about 260 ha from seven out of 10 villages. On the other hand, as in the case of seed corn and seed sun flower, only two collectors from one single village allocated 160 ha and 
30 ha for them, respectively. Additionally, for some other cash crops, such as tomato and seed tomato, though mentioned by the collectors as alternatives, were not cultivated because of their low market value in 2014.

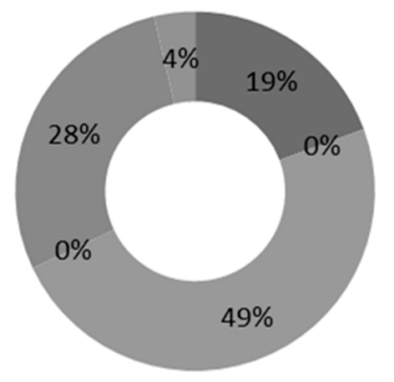

$$
\begin{aligned}
& \text { m seed corn } \\
& \text { m tomato } \\
& \text { m corn } \\
& \text { m seed tomato } \\
& \text { monion } \\
& \text { m seed sun flower }
\end{aligned}
$$

Figure 5. Crop distribution in the transferred farmland in LTC town in 2014. The percentage denotes the land area occupied by each type of crop: corn $(49 \%)$, onion $(28 \%)$, seed corn $(19 \%)$, seed sun flower $(4 \%)$, and tomato and seed tomato $(0 \%)$.

\subsection{Results of Interview Survey on Stakeholders' Satisfaction}

In this section, the results are analyzed from the interviews with different stakeholders of ALURT on the problems regarding to its long-term viability.

- Interview with the local government representatives

In NH town, the results of the interviews reveal that the users of ALURT have been declining since 2013. They mentioned that the collectors cannot afford the uniform high rent rate because some farmland was not of a good enough quality to make much profit. However, as the collectors cannot negotiate with farmers individually according to the difference in farmland fertility, and the intermediate agency has no incentive or duty to adjust the rent rate, many collectors had to quit ALURT. There are even reports of cases in which the collectors broke the contracts halfway through them. Because some farmers experienced the termination of contracts by some collectors, they claimed that they were also not likely to continue ALURT due to the economic loss last time. On the other hand, the interviews in LTC town confirm an increasing number of users in ALURT, mainly because the collectors can afford a high rent rate with the profits made from the high fertile farmland in LTC town. In addition, we conducted interviews in another town- $\mathrm{XH}$ town, who initiated ALURT as early as in 2009. The interviews in XH town reveal a similar decreasing trend of users within five years after its initialization, despite a high incentive from the farmers' side to participate in ALURT. In terms of the causes of the decrease, they mentioned the lack of an information platform for farmers and collectors. Although the farmers had high incentives to participate in ALURT, no supply-demand information had been provided to them through the intermediate agency, and no price negotiation between farmers and collectors could happen. This caused the decline in users of ALURT after several years of initialization in $\mathrm{XH}$ town despite the high willingness in participation inside the farmers in general.

- Interview with the demand side-collectors

The interviews in NH town reveal the difficulties to continue ALURT under the current regulation of the intermediate agency. The collectors claimed the rent set by the intermediate agency was the same for all farmers, despite the difference in soil quality of the farmland. This led to a cost too high for them to make a profit economically. Consequently, they could only confine themselves to certain profitable cash crops in the market, which in turn significantly reduced the diversity of crops in the transferred land ecologically. Despite this, the profit diminished again because the same types of crops saturated the market demand. Eventually, some collectors had to quit ALURT socially. Interviews in 
LTC town reveal similar financial issues, as some collectors asked for financial support such as low interest loans to carry on ALURT.

- Interview with the supply side—-farmers

The interviews in NH town reveal the difference in willingness of participation in ALURT. For example, in XF village, some farmers were not interested in participating in ALURT. Despite this, the centralized mode set by the intermediate agency required all farmers in the same production team to agree and participate in ALURT together, i.e., no individual contract is allowed. In $\mathrm{ZH}$ village, as $60 \%$ of the farmers were willing to join ALURT, the other $40 \%$ had no choice but to follow the majority and participate in ALURT as a whole. The farmers opposed to ALURT said they had problems with either the lower income from the rent than from farming by themselves economically, or social dependence on land as their traditional way of life. By transferring their land unwillingly, those farmers had to stay at home without any work to do. On the other hand, in another production team in $\mathrm{ZH}$ village, the whole production team refused to participate in ALURT as a whole, although some of the farmers did want to participate. When asked about the reasons for opposing ALURT, they listed, for example, no suitable collectors to meet most requirements from the farmers, and the fear of unexpected termination of the contracts from the collector side. In addition, another issue mentioned was the postponed payment made by the intermediate agency (see Section 3.1). Some farmers who had experienced postponed payment stated that they were afraid of corruption in the intermediate agency. They were unsatisfied with the current payment arrangement in ALURT and preferred prompt payment. We also found that most of the farmers who would like to participate in ALURT were old people who had lost their physical strength to do the hard work in their farmland. Interviews in LTC town and XH town were consistent with the interviews in $\mathrm{NH}$ town.

\section{Discussion}

In the vision in [30], Zhangye district should become an advanced agricultural area implemented with eco-agricultural high technologies including water economization of a high efficiency, breed industry, cultivation of a large scale, ecological rebuilding, agricultural industrialization, machining of agricultural or sideline products, and technological training. Unfortunately, the development of agriculture in this semi-arid area has already caused more desertification inside the oasis due to the overuse of water resources [39]. Other studies have suggested that a $4 \mathrm{~km}$ scale is the critical scale for an oasis to sustain itself [40]. For the sustainability of the oasis in HRB, the sustainable agriculture development in Zhangye district has become a crucial issue.

The problems of ALURT are common and persistent. For example, an earlier study done on ALURT in Northeast China observed similar phenomenons such as the urban migration of farmers and decreasing diversity in crops [41]. Given the even more limited water resources in HRB, the problems regarding the long-term viability of ALURT need to be properly addressed. Otherwise, ALURT cannot be an effective instrument for sustainable agriculture development in HRB.

In this section, we mainly discuss two theoretical issues related to the long-term viability of ALURT: diversity and balance.

- Diversity

Diversity has become a crucial concept in studies of sustainability in a complex system. Not only in natural systems, diversity in economic systems should be fostered as well, especially when the efficiency and diversity are in a trade-off relationship [42,43].

In general, as in [43], overly efficient systems without enough diversity are prone to collapse because they are out of the window of viability. In Figure 5, most land in ALURT has been used to cultivate only a limited number of crop types. Indeed, some crops are no longer cultivated in the land collected in ALURT. Our interview surveys confirmed that the big collectors, normally agricultural corporations, tended to use a large area of land for only one or two types of crops for maximum 
efficiency. This situation is further reinforced by the intermediate agency who only contracts a limited number of big collectors for its convenience. This change, in the long run, will highly likely reduce the diversity of crops. Ecologically, the lower the diversity of the crops, the greater the chance of a certain disaster (for example, disaster caused by a certain pest) happening in the ecosystem. Even in the sense of economics, several collectors who dominate the land shares could lead to over-supply of the same crop and saturation of the market, which would decrease the market price and the profit. This situation is partly confirmed in the interviews with big collectors in corn production $(49 \%$ land occupation, see Figure 5). Moreover, in risk management, it is also not wise to put all the eggs in one basket. Especially in the crucial sector of agriculture, food security can be threatened. For instance, if some of the big collectors encountered any problem (such as a financial problem), the agricultural production could be delayed or even stopped in a large area of farmland. In that case, a huge shock would be induced to the food market or even other sectors of the society.

Furthermore, diversity in an economic paradigm can also affect the long-term viability. As in the interview with collectors (Section 3.3), because they cannot negotiate with farmers individually to make a flexible rent rate, eventually they found the uniform rent rate for a whole production team usually non-profitable. For some other collectors, they found the labor shortage became another major problem for them in ALURT because of no information platform for labor exchange. On one hand, the collectors failed to find enough farmers working for them to cultivate the transferred land. As a result, they had to raise the labor wages too high to make a decent profit. On the other hand, there were farmers who lost their land and then had nothing to do at home. Given the diversity of the supply and demand requirements, an information platform provided by the intermediate agency could create a win-win situation, lowering the labor cost for the collectors and providing the farmers with jobs for a higher income.

In addition, social preference diversity is crucial to the long-term viability of ALURT as well. The different opinions towards the value of the farmland cause dissatisfaction in ALURT (see Section 3.3). Farmers who preferred to cultivate the land themselves were forced to follow the whole team and thus lost their land, and their preferred lifestyle. Farmers who preferred to participate in ALURT also had to give up sometimes, because of the difficulty in finding a proper collector to satisfy the diverse requirements of the whole team, or simply because most of the team members were opposed to ALURT.

\section{- Balance}

Balance is another key concept of sustainability in a complex system [43]. In particular, the power balance has a significant impact on user satisfaction by affecting the sustainability of self-governing organizations [44]. Therefore, the power imbalance needs to be taken into consideration when devising and modifying institutional structures governing common resources [44,45].

The agriculture land in ALURT, as a collective entity, is managed by the organizational structure indicated in Figure 2. The key powers, such as economic power (price adjustment and payment) and governance power (contract power), are all under the control of the intermediate agency (see Section 3.1). Moreover, the intermediate agency takes no risk and no responsibility at all in the actual execution process. The power is so imbalanced that fears of corruption have already arisen inside the farmers, which has become a concern of the farmers when they decide whether to join ALURT in the long run.

As no constant effort on price adjustment could be expected from the intermediate agency, and the farmers and collectors have no power over arguing for a price directly, the economic incentives of the users of ALURT are harmed by this imbalance. However, at the same time, the differences in rent prices by villages are still huge (see Figure 4). The rent difference in villages made by the intermediate agency might discourage most of the low rent rating villages following ALURT in future.

Therefore, a semi-decentralized regulation is suggested, in the spirit of power balance and diversity. In particular, the intermediate agency should not draft contracts with farmers or collectors by 
itself. Instead, it should supervise the contracting process between farmers and collectors, and permit effective contracts. In addition, it should be assigned to a role of an information platform, to provide both the collectors and the farmers the necessary information (for example, the supply-demand information of ALURT users). In this way, the collectors and farmers possess the power of negotiation in a wide range of conditions, which can attract more collectors and farmers to participate in ALURT; hence the big collector problem can be alleviated. Accordingly, it can possibly increase the satisfaction level of the users and thus the long-term viability of ALURT.

\section{Conclusions}

In this paper, the long-term viability of the ALURT policy in HRB is analyzed under a SURF framework. We identify the power imbalance that exists under the central regulation of the intermediate agency. We further confirm in the statistical data a decreasing trend in users, on-farm profits, and crop variety. From the interviews, we know that the dissatisfaction of the users was caused by the central regulation of the intermediate agency, because it limited the bargaining power of the users. We further discuss the key issues of diversity and balance related to ALURT. As a policy recommendation, we suggest a semi-decentralized regulation of ALURT, in addition to an information platform role redefined for the intermediate agency, for the long-term viability of ALURT.

Acknowledgments: This work was supported by the JSPS KAKENHI Grant Numbers 17K12855, as well as the Sumitomo Foundation, Heiwa Nakajima Foundation, Asahi Group Foundation, and the Ministry of Education, Culture, Sports, Science and Technology (MEXT) of Japan through the Grant-in-Aid Program for Leading Graduate Schools "Graduate Program in Sustainability Science-Global Leadership Initiative (GPSS-GLI)" of The University of Tokyo. This investigation was made possible by the cooperation of Sophia University and Cold and Arid Regions Environmental and Engineering Research Institute, Chinese Academy of Sciences. We would like to thank the staff and students in the Cold and Arid Regions Environmental and Engineering Research Institute, Chinese Academy of Sciences, for their help during the investigation. This investigation was made possible by the cooperation and assistance of many local people in the Zhangye City. We also would like to express our special thanks to Rey Sunbin Yoo for her kind English assistance.

Author Contributions: Tomohiro Akiyama conceived and designed the research; Ye Sun and Tomohiro Akiyama performed the data collection; Ye Sun analyzed the data; Tomohiro Akiyama contributed analysis tools; Ye Sun wrote the paper.

Conflicts of Interest: The authors declare no conflict of interest. The founding sponsors had no role in the design of the study; in the collection, analyses, or interpretation of data; in the writing of the manuscript, and in the decision to publish the results.

\section{References}

1. Ye, J. Land Transfer and the Pursuit of Agricultural Modernization in China. J. Agrar. Chang. 2015, 15, 314-337. [CrossRef]

2. Wu, H.; Ye, J. Hollow Lives: Women Left Behind in Rural China. J. Agrar. Chang. 2016, 16, 51-70. [CrossRef]

3. Ye, J.; Pan, L. Differentiated Childhoods: Impacts of Rural Labor Migration on Left-behind Children in China. J. Peasant Stud. 2011, 38, 355-377. [CrossRef]

4. Ye, J. Grassroots Voices/Left-behind Children: The Social Price of China's Economic Boom. J. Peasant Stud. 2011, 38, 613-650. [CrossRef]

5. Ye, J.; He, C.; Liu, J.; Wang, W.; Chen, S. Left-behind elderly: Shouldering a disproportionate share of production and reproduction in supporting China's industrial development. J. Peasant Stud. 2017, 44, 971-999. [CrossRef]

6. Wang, L. A Study on China's Rural Land Transfer Policy in the Process of Urbanization from the Perspective of Punctuated-Equilibrium Theory. Public Policy Soc. Gov. 2014, 2, 191-199.

7. Du, Y.; Sun, B. The Development of Chinese Agricultural Land Transfer System: Transaction, Concentration and Commercialization. J. Agric. Sci. 2011, 3, 269. [CrossRef]

8. Gibson, R.B. Beyond the pillars: Sustainability assessment as a framework for effective integration of social, economic and ecological considerations in significant decision-making. J. Environ. Assess. Policy Manag. 2006, 8, 259-280. [CrossRef] 
9. Yusuf, T.M.; Adewumi, M.O. Analysis of Off-Farm Employment and Poverty Status of Farming Households in Kwara State, Nigeria. Int. J. Sci. Res. Innov. Technol. 2016, 3, 167-180.

10. VanWey, L.; Vithayathil, T. Off-farm Work among Rural Households: A Case Study in the Brazilian Amazon. Rural Sociol. 2013, 78, 29-50. [CrossRef] [PubMed]

11. Balisacan, A.M. Agricultural Growth, Landlessness, Off-Farm Employment, and Rural Poverty in the Philippines. Econ. Dev. Cult. Chang. 1993, 41, 533-562. [CrossRef]

12. Woldehanna, T.; Oskam, A. Off-farm Employment and Income Inequality: The implication for Poverty Reduction Strategy. Ethiop. J. Econ. 2004, 9, 40-57.

13. Castro, W.V.; Heerink, N.; Shi, X.; Qu, W. Water savings through off-farm employment? China Agric. Econ. Rev. 2010, 2, 167-184. [CrossRef]

14. Yin, N.; Huang, Q.; Yang, Z.; Wang, Y. Impacts of Off-Farm Employment on Irrigation Water Efficiency in North China. Water 2016, 8, 452. [CrossRef]

15. Waas, T.; Hugé, J.; Block, T.; Wright, T.; Benitez-Capistros, F.; Verbruggen, A. Sustainability assessment and indicators: Tools in a decision-making strategy for sustainable development. Sustainability 2014, 6, 5512-5534. [CrossRef]

16. Pope, J.; Morrison-Saunders, A.; Annandale, D. Applying sustainability assessment models. Impact Assess. Proj. Apprais. 2005, 23, 293-302. [CrossRef]

17. Morrison-Saunders, A.; Therivel, R. Sustainability integration and assessment. J. Environ. Assess. Policy Manag. 2006, 8, 281-298. [CrossRef]

18. Pope, J.; Annandale, D.; Morrison-Saunders, A. Conceptualising sustainability assessment. Environ. Impact Assess. Rev. 2004, 24, 595-616. [CrossRef]

19. Sala, S.; Ciuffo, B.; Nijkamp, P. A systemic framework for sustainability assessment. Ecol. Econ. 2015, 119, 314-325. [CrossRef]

20. Chen, L.; Hu, L. Studies on Chinese Farmland Use Rights Transfer System. Adv. Econ. Bus. 2014, 2, 303-307. [CrossRef]

21. Hu, N.; Li, X.; Luo, L.; Zhang, L. Ancient Irrigation Canals Mapped from Corona Imageries and Their Implications in Juyan Oasis along the Silk Road. Sustainability 2017, 9, 1283. [CrossRef]

22. Song, W.; Zhang, Y. Expansion of agricultural oasis in the Heihe River Basin of China: Patterns, reasons and policy implications. Phys. Chem. Earth Parts A/B/C 2015, 89-90, 46-55. [CrossRef]

23. Hu, X.; Lu, L.; Li, X.; Wang, J.; Guo, M. Land Use/Cover Change in the Middle Reaches of the Heihe River Basin over 2000-2011 and Its Implications for Sustainable Water Resource Management. PLoS ONE 2015, 10, e0128960. [CrossRef] [PubMed]

24. Wang, Y.; Xiao, H.; Wang, R. Water Scarcity and Water Use in Economic Systems in Zhangye City, Northwestern China. Water Resour. Manag. 2009, 23, 2655-2668. [CrossRef]

25. Zhang, J. Barriers to water markets in the Heihe River basin in northwest China. Agric. Water Manag. 2007, 87, 32-40. [CrossRef]

26. Peng, H.; Cheng, G.; Xu, Z.; Yin, Y.; Xu, W. Social, economic, and ecological impacts of the "Grain for Green" project in China: A preliminary case in Zhangye, Northwest China. J. Environ. Manag. 2007, 85, 774-784. [CrossRef] [PubMed]

27. Wen, X.; Wu, Y.; Lee, L.; Su, J.; Wu, J. Groundwater flow modeling in the Zhangye Basin, Northwestern China. Environ. Geol. 2007, 53, 77-84. [CrossRef]

28. Wen, X.; Wu, J.; Si, J. A GIS-based DRASTIC model for assessing shallow groundwater vulnerability in the Zhangye Basin, northwestern China. Environ. Geol. 2009, 57, 1435-1442. [CrossRef]

29. Qin, D.; Qian, Y.; Han, L.; Wang, Z.; Li, C.; Zhao, Z. Assessing impact of irrigation water on groundwater recharge and quality in arid environment using CFCs, tritium and stable isotopes, in the Zhangye Basin, Northwest China. J. Hydrol. 2011, 405, 194-208. [CrossRef]

30. Fang, C.; Huang, J.; Liu, Y. Thoughts on constructing the demonstrating areas of the ecological rebuilding and economic sustainable development in Hexi Region. Chin. Geogr. Sci. 2002, 12, 14-22. [CrossRef]

31. Zhang, J.; Zhang, F. Mutual monitoring in a tradable water rights system: A case study of Zhangye City in Northwest China. Agric. Water Manag. 2008, 95, 331-338. [CrossRef]

32. Zhang, L.; Zhu, X.; Heerink, N.; Shi, X. Does output market development affect irrigation water institutions? Insights from a case study in northern China. Agric. Water Manag. 2014, 131, 70-78. [CrossRef] 
33. Takahashi, T.; Aizaki, H.; Ge, Y.; Ma, M.; Nakashima, Y.; Sato, T.; Wang, W.; Yamada, N. Agricultural water trade under farmland fragmentation: A simulation analysis of an irrigation district in northwestern China. Agric. Water Manag. 2013, 122, 63-66. [CrossRef]

34. Wang, Y.; Xiao, H.; Lu, M. Analysis of water consumption using a regional input-output model: Model development and application to Zhangye City, Northwestern China. J. Arid Environ. 2009, 73, 894-900. [CrossRef]

35. Ott, K.; Kerschbaumer, L.; Köbbing, J.F.; Thevs, N. Bringing Sustainability Down to Earth: Heihe River as a Paradigm Case of Sustainable Water Allocation. J. Agric. Environ. Ethics 2016, 29, 835. [CrossRef]

36. Waite, M. SURF framework for a sustainable economy. J. Manag. Sustain. 2013, 3, 25. [CrossRef]

37. Li, N.; Wang, X.; Shi, M.; Yang, H. Economic Impacts of Total Water Use Control in the Heihe River Basin in Northwestern China-An Integrated CGE-BEM Modeling Approach. Sustainability 2015, 7, 3460-3478. [CrossRef]

38. Ministry of Agriculture of the People's Republic of China. Available online: http:/ /www.moa.gov.cn/ztzl/ bxwhdy/gongzdt/201503/t20150318_4444832.htm (accessed on 6 December 2017). (In Chinese)

39. Luo, F.; Qi, S.; Xiao, H. Landscape change and sandy desertification in arid areas: A case study in the Zhangye Region of Gansu Province, China. Environ. Geol. 2005, 49, 90-97. [CrossRef]

40. Gao, Y.; Chen, Y.; Lü, S. Numerical simulation of the critical scale of oasis maintenance and development in the arid regions of Northwest China. Adv. Atmos. Sci. 2004, 21, 113-124. [CrossRef]

41. Yu, Q.; Wu, W.; Verburg, P.H.; Vliet, J.V.; Yang, P.; Zhou, Q.; Tang, H. A survey-based exploration of land-system dynamics in an agricultural region of Northeast China. Agric. Syst. 2013, 121, 106-116. [CrossRef]

42. Ulanowicz, R.E.; Goerner, S.J.; Lieater, B.; Gomez, R. Quantifying sustainability: Resilience, efficiency and the return of information theory. Ecol. Complex. 2009, 6, 27-36. [CrossRef]

43. Goerner, S.J.; Lietaer, B.; Ulanowicz, R.E. Quantifying economic sustainability: Implications for free-enterprise theory, policy and practice. Ecol. Econ. 2009, 69, 76-81. [CrossRef]

44. Kadirbeyoglu, Z;; Özertan, G. Power in the Governance of Common-Pool Resources: A comparative analysis of irrigation management decentralization in Turkey. Environ. Pol. Gov. 2015, 25, 157-171. [CrossRef]

45. Agrawal, A. Sustainable Governance of Common-Pool Resources: Context, Methods, and Politics. Ann. Rev. Anthropol. 2003, 32, 243-262. [CrossRef]

(C) 2018 by the authors. Licensee MDPI, Basel, Switzerland. This article is an open access article distributed under the terms and conditions of the Creative Commons Attribution (CC BY) license (http:/ / creativecommons.org/licenses/by/4.0/). 